\title{
De la radicalización política a la defensa de derechos humanos en París. Dos trayectorias conectadas de reconversión militante (Envar El Kadri y François Gèze, 1968-1983)
}

Moira Cristiä

\section{RESUMEN}

El artículo analiza las trayectorias militantes del argentino Envar El Kadri y del francés François Gèze como casos testigo de las conexiones que confluyeron desde la radicalización de amplios sectores de la izquierda internacional en torno a 1968 a la férrea defensa de los derechos humanos a principios de los ochenta. Si aún en 1975 ambos actores compartían un discurso antimperialista y apoyaban procesos revolucionarios, en pocos años, tanto El Kadri como Gèze se posicionaron claramente en la defensa de los derechos humanos, repudiando a la dictadura argentina. Desde una perspectiva de historias conectadas, el trabajo demuestra que el pasaje del apoyo de la violencia revolucionaria a la estricta denuncia humanitaria internacional no fue un fenómeno exclusivamente latinoamericano. Por el contrario, encarnó un proceso de transformación del clima político global que se manifestó con sus particularidades en distintas latitudes.

Palabras clave: trayectorias; historia conectada; reconversión militante; revolución; derechos humanos.

\section{Da radicalização política à defesa dos direitos humanos em Paris. Duas trajetórias conectadas de reconversáo militante (Envar El Kadri e François Gèze, 1968-1983)}

\section{RESUMO}

$\mathrm{O}$ artigo analisa as trajetórias militantes do argentino Envar El Kadri e do francês François Gèze como testemunhos das conexóes que decorreram da radicalização de amplos setores

DOI: http://dx.doi.org/10.1590/2237-101X02204812

Artigo recebido em 3 de julho de 2020 e aceito para publicação em 24 de novembro de 2020.

* Pesquisadora do Instituto de Investigaciones Gino Germani, Buenos Aires - Argentina. E-mail: moicristia@gmail.com. ORCID: https://orcid.org/0000-0001-5829-4126. 
De la radicalización política a la defensa de Derechos humanos en París. Dos trayectorias CONeCTAdas De Reconversión militante (Envar El Kadri y François Gèze, I 968 -I983)

\title{
Moira Cristiá
}

da esquerda internacional por volta de 1968 à feroz defesa dos direitos humanos no início dos anos 1980. Se, ainda em 1975, ambos os atores compartilhavam um discurso antiimperialista e apoiavam os processos revolucionários, em poucos anos, tanto El Kadri quanto Gèze se posicionaram claramente em defesa dos direitos humanos, repudiando a ditadura argentina. Da perspectiva das histórias conectadas, o trabalho mostra que a mudança do apoio à violência revolucionária para a estrita denúncia humanitária internacional não foi um fenômeno exclusivamente latino-americano. Ao contrário, corporificou um processo de transformaçáo do clima político global que se manifestou com suas particularidades em diferentes latitudes.

Palavras-chave: trajetórias; histórias conectadas; reconversão militante; revolução; direitos humanos.

\section{From political radicalization to the defense of human rights in Paris. Two connected trajectories of militant reconversion (Envar El Kadri and François Gèze, 1968-1983)}

\begin{abstract}
The article analyzes the militant trajectories of the Argentinean Envar El Kadri and the Frenchman François Gèze as case studies of the connections that emerged during the radicalization of broad sectors of the international left around 1968 and the outpouring of support for the defense of human rights at the beginning of the 1980s. As late as 1975, both actors shared an anti-imperialist discourse and support for revolutionary movements, but in a few years, both El Kadri and Gèze positioned themselves clearly in support of the defense of human rights, repudiating the Argentine dictatorship. From a perspective of connected stories, this paper argues that the change from supporting revolutionary violence to a strict international humanitarian denunciation was not exclusively a Latin American phenomenon. On the contrary, it was a process of global political transformation that had particularities in different regions.
\end{abstract}

Keywords: trajectories; connected history; militant reconversion; revolution; human rights.

\section{Introducción}

"Cada lucha de un pueblo hermano es parte de nuestro proceso nacional de liberación. Sus victorias son las nuestras, tanto como lo son sus derrotas. Porque la lucha contra la dominación colonialista y la explotación de 
De la radicalización política a la defensa de Derechos humanos en París. Dos trayectorias CONeCTAdas De Reconversión militante (Envar El Kadri y François Gèze, I 968 -I983)

\section{Moira Cristiá}

los pueblos, es nuestra propia lucha" (EL KADRI, 1975, tomo IV, p. $157^{1}$ ).

"En 1973, mientras que las botas de los militares aplastaban sucesivamente Bolivia, Uruguay, Chile, todo parecia indicar que Argentina entraba, por lo contrario, en un proceso de democratización. El regreso al poder de Juan Domingo Perón - después de dieciocho años de exilio - provocaba el entusiasmo de todo el pueblo argentino y en particular de los guerrilleros montoneros, quienes habian derramado su sangre para que Perón pudiera volver al país y encabezar la lucha contra el imperialismo estadounidense y brasileño. Pero la fiesta rápidamente, se volvería desastre"2 (GÈZE; LABROUSSE, 1975, introducción).

Los dos epígrafes seleccionados, escritos el mismo año por un argentino y dos franceses respectivamente, expresan una interpretación antimperialista del conflicto político argentino que, en su concepción, admite la violencia como método legítimo de lucha. En ambos textos, se percibe una idea del sacrificio individual en la búsqueda de una justicia social y, también en ambos casos, esta postura se verá pronto transformada. Los rasgos del discurso adquirirán nuevas formas, para posicionarse firmemente en la defensa de los derechos humanos al repudiar a la dictadura argentina. Esta evolución no parece ser una excepción, sino más bien un fenómeno extendido en aquellos sectores politizados que estos actores integraban, por lo que una abundante bibliografía abordó y ensayó explicaciones que dieran cuenta de aquel giro histórico. El arco temporal que va del proceso de politización latinoamericano de los sesenta-setenta a la coyuntura represiva de los setenta-ochenta evidenció ese paso entre la eminencia de un discurso o "narrativa" revolucionaria a uno centrado en los derechos humanos. ¿Fue una verdadera transformación del diagnóstico de esa coyuntura? ¿O acaso se trató más bien de una postura estratégica? ¿A qué factores podría atribuirse este giro en la percepción de su tiempo?

Las explicaciones historiográficas sobre América Latina tienden a acentuar la adopción utilitaria o estratégica de parte de los actores revolucionarios de esa región de nuevos valores y de un lenguaje que permitiera dar batalla a la dictadura militar, fruto tanto de los contactos con redes transnacionales como de la inmersión en una nueva lógica como consecuencia del exilio. Si los derechos humanos, establecidos con la firma de la Declaración de Derechos Humanos de las Naciones Unidas de 1948 como una serie de valores defendidos por una

\footnotetext{
${ }^{1}$ Archivo personal de Liliana Andreone, París.

${ }^{2}$ La traducción y los resaltados son nuestros.
} 
De la radicalización política a la defensa de derechos humanos en París. Dos trayectorias CONeCtadas De reconversión militante (Envar El Kadri y François Gèze, I 968 -I983)

\section{Moira Cristiá}

comunidad internacional, fueron por largo tiempo identificados con el anticomunismo en el marco de la Guerra Fría, durante las dictaduras en el Cono Sur diversos grupos de izquierda establecieron una estrecha cooperación con organismos internacionales que abogaban por ellos. Lejos de sostener que se trata de una verdadera "conversión", algunos estudios resaltan la convivencia, según el contexto de producción y el destinatario de ambos repertorios discursivos y simbólicos (MARKARIAN, 2006; CRENZEL, 2013; COPELLO, 2019b). Sin embargo, otros trabajos complejizan ese panorama, demostrando que, si bien existió una incorporación táctica inicial, en una parte de esos grupos también fue acompańado del nacimiento de un nuevo paradigma con la modificación del contexto histórico (JENSEN, 2019; VECCHIOLI, 2008) en algunos casos resaltando la adaptación y "traducción" de ideas (COPELLO, 2019a). Otros trabajos acentúan que este camino, si bien mayoritario, no fue único, rescatando las diversas derivas de los militantes revolucionarios con el regreso de la democracia en los países del Cono Sur, como el apoyo de otros procesos revolucionarios (MARCHESI, 2019; CORTINA, 2017, GREDA PORTERO; HELM, 2016). La hipótesis que se propone en este trabajo es que esta evolución no fue exclusiva de los actores revolucionarios latinoamericanos, sino que puede pensarse como un proceso de transformación del clima político global que se manifestó con sus particularidades en distintas latitudes.

Este artículo se propone analizar específicamente las trayectorias militantes del argentino Envar El Kadri y del francés François Gèze, abordándolos como casos testigo ${ }^{3}$ de las conexiones que confluyeron desde la radicalización de amplios sectores de izquierda internacional de fines de los años sesenta a la priorización de la defensa de los derechos humanos una década más tarde ${ }^{4}$. En el estudio de ese fenómeno, consideraremos en los casos seleccionados los contextos de su "politización" (FILLIEULE, 2001; MATHIEU, 2018) y las "incidencias biográficas de compromiso" (PAGIS, 2011), es decir, los modos en los que las experiencias de militancia condicionaron las decisiones vitales posteriores. Así, adoptando esos conceptos y reflexiones del campo de la sociología de la militancia que estudió el proceso francés de 1968 en un tiempo más largo que el coyuntural - proceso del que Géze fue parte -, intentaremos echar algo de luz sobre ese fenómeno que consideramos transnacional. De París a Buenos Aires y viceversa, las circulaciones de estos actores acompañan el proceso descrito, colaborando en ciertas experiencias colectivas y confluyendo en articular la denuncia de la represión de la dictadura argentina desde el centro de Europa.

\footnotetext{
${ }^{3}$ Según Bernard (2018), "la historia conectada puede y debe enriquecerse por los estudios de caso" ya que el análisis de escala micro permite reflexionar en torno a las circulaciones y, en consecuencia, visibilizar las tramas que conectan las historias nacionales.

${ }^{4}$ Un caso cercano a estas experiencias es el de Régis Debray: un estudiante de filosofía de una familia tradicional que pasó de convertirse en intelectual comprometido con la Revolución Cubana en los años sesenta a consejero de Estado de Francia en los ochenta. Su misión en Bolivia en 1967 le valió la prisión por 4 años y motivó una significativa campaña de solidaridad internacional (CUCCHETTI, 2018; MARCHESI, 2018, p. 46-51).
} 
De la radicalización política a la defensa de derechos humanos en París. Dos trayectorias CONeCtadas De ReCONVERsión militante (EnVar El KadRi y François Gèze, I 968 -I983)

\section{Moira Cristiá}

Para reconstruir sus trayectorias y las dinámicas compartidas, se cruzarán distintos tipos de documentos escritos con fuentes orales y se evocará bibliografía reciente, buscando iluminar cómo estas historias nacionales se encuentran "conectadas" (DOUKI; MINARD, 2007; LEVITT; KHAGRAM, 2008).

En este sentido, el presente artículo asume la propuesta de Gruzinski de que el/la historiador/a se transforme en "una suerte de electricista capaz de reestablecer las conexiones continentales e intercontinentales que las historiografías nacionales se ingeniaron por largo tiempo de desconectar o de escamotear impermeabilizando sus fronteras" (2001, p. 87). La apuesta metodológica se centrará en el análisis en los actores sociales y en sus interacciones, dando cuenta de la simultaneidad de esferas de acción en las que intervienen. Si bien nos ocupamos de experiencias singulares para construir un objeto de análisis acotado para este trabajo, éstas fueron seleccionadas porque componen diferentes experiencias colectivas, algunas de las cuales son explicitadas sin pretender reconstruirlas exhaustivamente.

Los actores en los que este artículo se focaliza son de diferentes nacionalidades, pero experimentaron una similar transformación desde la adscripción a una narrativa revolucionaria internacionalista a la defensa de los derechos humanos. Se trata de dos historias de vida con ciertas características comunes, como el haber sufrido un giro radical en 1968 - en el caso de Gèze al implicarse en las revueltas francesas de mayo, en el de El Kadri al emprender una guerrilla rural en Argentina -, luego vivenciado un "trasplante" geográfico y cultural transatlántico - aunque en coyunturas ligeramente desplazadas en el tiempo -, atravesando el océano en sentidos opuestos y provocados por distintas circunstancias. Dichas mudanzas temporarias al otro lado del Atlántico les permitieron vincularse entre ellos y transitar una serie de experiencias de militancia e iniciativas culturales de denuncia compartidas. Este proceso derivó en su cooperación en formaciones como el COBA (Collectifpour le boycott de l'organisation par l'Argentine de la coupe du monde de football) en 1978/79 y más tarde en la campaña por ese país de AIDA (Association Internationale de Défense des Artistes victimes de la répression dans le monde). En esta nueva organización, uno de sus más ambiciosos proyectos fue la elaboración de un libro en 1981, de una difusión amplia en ese continente, del cual Gèze y El Kadri fueron actores clave. En suma, la selección de las trayectorias responde a sus particularidades, así como a cierto protagonismo en determinados procesos colectivos. En este artículo, se dedicará una parte a reconstruir cada una de esas dos trayectorias personales, aportando elementos contextuales para su análisis, y una tercera al momento de auge de la colaboración entre los actores, estudiados en diferentes asociaciones e interacciones, de manera de reflexionar sobre la transformación en el tiempo de su concepción sobre la violencia y los derechos humanos. 
De la radicalización política a la defensa de Derechos humanos en París. Dos trayectorias CONeCTAdas De Reconversión militante (Envar El Kadri y François Gèze, I 968 -I983)

\section{Moira Cristiá}

\section{El Kadri: de la cultura militante a la militancia de la cultura}

Nacido en Río Cuarto - provincia de Córdoba - en 1941, Envar "Cacho" El Kadri participó de la resistencia peronista durante los años de la proscripción ${ }^{5}$, contexto que imprimió a la época una extendida sensación de injusticia y la voluntad de implicarse para transformar la situación. En septiembre de 1968, a casi un año del asesinato del Che Guevara en Bolivia evento que impactó en las juventudes políticamente comprometidas en un plano internacional -, se embarcó en el intento fallido de guerrilla rural en Taco Ralo (Tucumán), encontrándose entre los fundadores de las Fuerzas Armadas Peronistas. Por su acción política sufrió prisión en dos ocasiones (de 1960 a 1963, y de 1968 a 1973), tortura, amenazas de muerte y finalmente el exilio (ANGUITA; CAPARRÓS, 2006; CERSOSIMO, 2008). Puesto que su padre era libanés y tenía familiares en ese país, al verse obligado a salir de Argentina el 1 de enero de 1975, El Kadri se refugió inicialmente en Beirut (ROBLEDO, 2018, p. 104-114).

Aprovechando sus contactos previos con militantes palestinos e interesado por la experiencia de esa resistencia, "Cacho" entrevistó a integrantes del movimiento, observó, analizó y escribió un libro sobre ese conflicto durante su estadía en Medio Oriente, pensándolo como un ejemplo para la lucha necesaria en América Latina. Palestina, una lucha del Tercer Mundo reflexiona sobre las particularidades del caso acentuando la fraternidad entre los pueblos en una solidaridad internacional de movimientos de liberación nacional contra las potencias colonialistas (EL KADRI, 1975). Sin embargo, el cambio de contexto y el devenir histórico, postergaron indefinidamente su publicación. ¿Por qué nunca publicó ese libro, aunque ya se encontraba terminado y en condiciones para su lanzamiento público?

Figura 1: Manuscrito El Kadri, Envar, Palestina, una lucha del tercer mundo, (mimeo), 1975

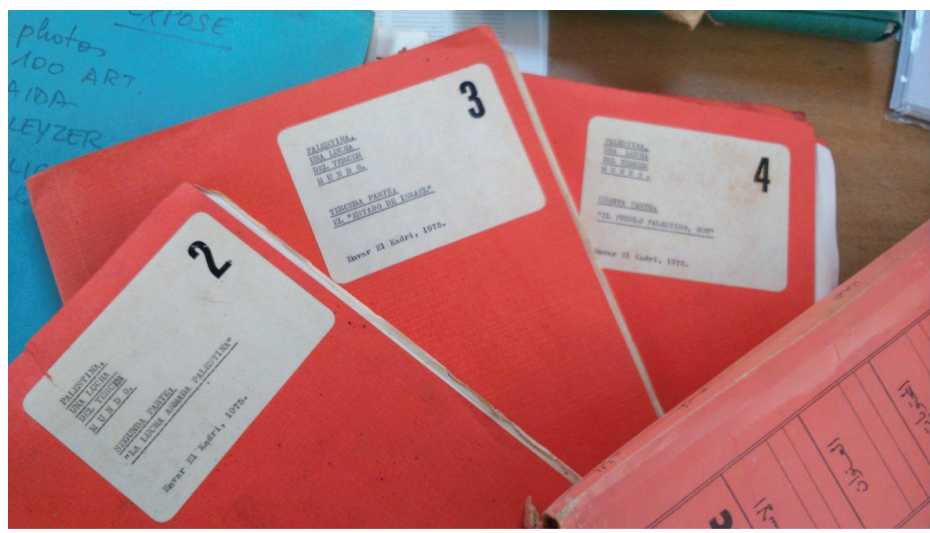

Fuente: Archivo personal de Liliana Andreone

\footnotetext{
${ }^{5}$ Tras el derrocamiento de Juan Domingo Perón en 1955, el partido que éste había fundado fue proscripto y toda referencia al mismo vedada. Desde entonces, distintas iniciativas de resistencia se expresaron tanto en pequeńos actos de desobediencia como con acciones violentas.
} 
De la radicalización política a la defensa de derechos humanos en París. Dos trayectorias CONeCtadas De Reconversión militante (Envar El Kadri y François Gèze, I 968 -I983)

\section{Moira Cristiá}

Al dejar el Líbano, El Kadri se instaló en Madrid, donde se reunió con su pareja y compañera de militancia - Liliana Andreone - quien logró salir de Argentina el 22 de marzo de 1976, sólo dos días antes del golpe de Estado. Abogada recientemente recibida y militante del Peronismo de Base, Liliana provenía de una familia de Córdoba y había crecido en Buenos Aires, donde su compromiso se desarrolló próximo a la corriente católica tercermundista. Allí colaboró inicialmente en la alfabetización en "villas miseria" ${ }^{\text {, }}$ camino que la acercó a un círculo de militantes de larga trayectoria. Sus diferencias respecto a continuar las acciones armadas tras la restauración de la democracia en 1973, sus críticas al militarismo que emprendían las organizaciones en ese marco, y el acecho de los grupos paramilitares represivos que forzaron a El Kadri a exiliarse, impulsaron a Liliana a ir a su encuentro.

Al poco tiempo de instalarse en la capital española, la pareja fue obligada a salir del país tras la detención de El Kadri, sospechado por los servicios de inteligencia locales, en un probable diálogo con agentes argentinos ${ }^{7}$. En tanto el allanamiento de su departamento se realizó en su ausencia, Liliana se refugió en la casa del fotógrafo y compatriota José "Pepe" Lamarca, logró ubicar a su compañero a pesar de la negativa inicial de la policía de brindarle información, realizó múltiples denuncias apoyada por el periodista español Manolo Revueltas ${ }^{8}$ y gestionó un pasaje para que su compañero saliera del país financiado por Amnesty International. Sin embargo, antes de que ese movimiento se concretara, las fuerzas de seguridad españolas lo condujeron y abandonaron en la frontera con Francia. Librado a su suerte con su pasaporte, pero sin dinero, El Kadri consiguió llegar a París gracias a la solidaridad de desconocidos?.

En París, la pareja fue recibida y alojada el primer tiempo por el actor Norman Brinski y su esposa Marie-Pascale Chevance Bertin, quienes habían militado en el Peronismo de Base y entonces vivían en el departamento de los padres de la psicoanalista francesa ${ }^{10}$. Después de algunos trabajos informales, Liliana comenzó a trabajar en el taller del Théâtre du Soleil en agosto de 1976, especializándose pronto en las relaciones públicas del teatro.

\footnotetext{
${ }^{6}$ En Argentina se denomina "villas miseria" a los asentamientos informales de viviendas precarias, generalmente en las afueras de las ciudades.

${ }^{7}$ Liliana recuerda que su compañero notó haber sido identificado por "servicios" argentinos en el bar madrileño del que era propietario el bailarín de flamenco Antonio Gades, al que solía acudir un público progresista (ENTREVISTA de la autora a Liliana Andreone, París, 28 abr. 2016. Existen numerosas evidencias de la prolongación extraterritorial de las actividades de inteligencia y de acciones represivas de la dictadura argentina (consultar BOIMVASER, 2000; SLATMAN, 2012; FERNÁNDEZ BARRIO; GONZÁLEZ TIZÓN, 2020).

${ }^{8}$ En ese contexto, el periodista español publicó dos artículos en el diario El País denunciando la represión de la dictadura argentina y sus estrategias para negar o disimular sus crímenes de Estado. Cf. REVUELTA, Manuel. Muerte del poeta Francisco Urondo. El País, 3 jul. 1976; y Las 'campañas orquestadas', denunciadas por el gobierno argentino. El País, 26 ago. 1976.

${ }^{9}$ ENTREVISTA de la autora a Liliana Andreone. París, 28 abr. 2016.

${ }^{10}$ ENTREVISTA de la autora a Marie-Pascale Chevance Bertin. París, 5 mayo 2016.
} 
De la radicalización política a la defensa de Derechos humanos en París. Dos trayectorias CONeCTAdas De Reconversión militante (Envar El Kadri y François Gèze, I 968 -I983)

\section{Moira Cristiá}

Como acuerdo conyugal, la pareja se sostenía económicamente por el trabajo de Liliana, mientras Cacho -además de retomar estudios de Derecho -, se dedicaba plenamente a la militancia en tareas de denuncia y solidaridad, actividades que Liliana secundaba al terminar su horario laboral ${ }^{11}$.

Fue también al llegar a la capital francesa que El Kadri retomó contacto con François Gèze, quien lo había entrevistado varias veces en Buenos Aires. A través de él, Andreone y El Kadri se vincularon con círculos militantes franceses y exiliados de otras procedencias. Según Fernando Solanas, director de cine argentino también exiliado en Francia, ellos sentían cierto aislamiento político en ese contexto por sus discrepancias respecto del accionar de las organizaciones político-militares ${ }^{12}$. Sus desacuerdos principalmente con Montoneros se vinculaban a la dirección que la organización emprendía en el exilio, que cuajaría en el proyecto de la "contraofensiva"13. Dicho proyecto de retorno de militantes al país para enfrentar militarmente la dictadura generó, además de discusiones entre los argentinos, la ruptura de un ala de la organización (CONFINO, 2019). Por fuera de ese ámbito discordante de la comunidad argentina allí exiliada, la militancia en agrupaciones francesas y con artistas de otras nacionalidades permitió a estos actores continuar con el objetivo de denunciar la represión militar, a la vez que lograron - como señaló Franco - una nueva "y auténtica identificación compartida" en torno a los derechos humanos (2008, p. 160-161). Fue en ese marco que Solanas, El Kadri y Andreone integrarán, en 1979, AIDA.

\section{Gèze: París/Buenos Aires/París}

Cuando El Kadri conoció a François Gèze, el ingeniero francés residía en Argentina. Entre fines de 1973 y principios de 1975 cumplía allí, en reemplazo del servicio militar, su contribución al Estado francés en la cooperación internacional. Además de aquella función que desempeńaba en el centro de documentación de la Embajada de Francia, Gèze continuaba su militancia solapadamente al colaborar - bajo el pseudónimo de Juan Carlos Ruso - como corresponsal de la revista francesa de "extrema izquierda" Politique Hebdo. También aprovechó su estadía para recoger información a través de documentos y entrevistas sobre la situación local con la intención de escribir un libro que publicaría una vez regresado a Francia ${ }^{14}$.

${ }^{11}$ En dos entrevistas del momento de regreso a Argentina, El Kadri señala este apoyo, compromiso y colaboración fundamental de su pareja durante aquellos ańos. AZNARES, Carlos. Reportaje a El Kadri. Caras y Caretas, n. 2.209, abr. 1984; MONCALVILLO, Mona. Entrevista a Envar El Kadri. Humor, n. 126, p. 55, abr. 1984. Ambas entrevistas aparecen reunidas y publicadas en Cersósimo (2008).

${ }^{12}$ PEÑA, Fernando Martín; PONCE, Alberto. Cómo se hizo "El exilio de Gardel”, 85 min., Argentina, 2010.

${ }^{13}$ ENTREVISTA de la autora a Fernando Solanas. Olivos, 29 abr. 2017.

${ }^{14}$ ENTREVISTA de Thomas Baumgartner a François Gèze. Programa radial “À voix nue”, Radio France Culture, 21 oct. 2013. Disponible en: https://www.franceculture.fr/emissions/voix-nue/francois-geze-15. 
De la radicalización política a la defensa de derechos humanos en París. Dos trayectorias CONeCtadas De Reconversión militante (Envar El Kadri y François Gèze, I 968 -I983)

\section{Moira Cristiá}

Según su relato, fue el haber atravesado la efervescencia de mayo del 68 cuando tenía 20 años de edad, lo que torció su destino en apariencia natural, experimentando una profunda politización al calor de esos acontecimientos. Como parte de un efecto amplio en su generación - aunque en distintos grados -, esa intensa vivencia colectiva juvenil instituyó en él una vocación por la injerencia política ${ }^{15}$. En ese período, mientras Gèze cursaba la clase preparatoria científica en Toulouse (formación para rendir los concursos de ingreso a las "grandes escuelas"16), participó intensamente en manifestaciones y acciones de solidaridad con obreros en huelga ${ }^{17}$. Proveniente de una familia de clase media profesional y de un medio que lo habría conducido probablemente a ocupar un puesto alto o directivo en una empresa, esta coyuntura transformó completamente sus perspectivas, conduciéndolo luego a fracturar - junto a parte de su generación que se politizó en esos años - aquel mandato familiar. Al año siguiente, durante sus estudios de Ingeniería en París en la prestigiosa École des Mines, se vinculó con militantes del Partido Socialista Unificado (PSU), adhiriendo a esa tendencia de "extrema izquierda" del espectro político francés ${ }^{18}$.

Después de un viaje iniciático a América Latina en 1971 junto a su pareja, regresó nuevamente a Chile al año siguiente para conocer más profundamente la situación de ese país bajo el gobierno de Salvador Allende. El entusiasmo que significaba esa experiencia latinoamericana para amplios sectores de la izquierda francesa motivó la visita de esas tierras y, tras el golpe de Estado, una consecuente acogida de exiliados e intensa denuncia de la dictadura pinochetista (MOINE, 2015). Justificado por la especialización de Gèze en minas, su cooperación debería cumplirse desde septiembre de 1973 en Chile en una empresa minera de cobre, pero - como consecuencia del golpe de Estado - fue finalmente designado al país vecino ${ }^{19}$.

Siete años más joven que su contemporáneo argentino, Gèze entrevistó a El Kadri así como a distintos líderes y militantes, buscando entender la situación política argentina, realidad compleja y de difícil comprensión para los parámetros europeos que intentó plasmar en el libro que publicaría al regresar a París en 1975. El mismo fue coescrito junto al Doctor en Sociología y Letras Alain Labrousse, al que le dieron por título Argentine: Révolution et contre-révolutions (1975). Su co-autor también había vivido en la región,

Acceso en: 14 mayo 2019.

${ }^{15}$ El estudio empírico de Pagis (2011) demuestra una diversidad de "incidencias biográficas" del militantismo de mayo del 68, desarmando la idea monolítica de una "generación 68". El caso de Gèze coincide con el modelo de aquellos cuya intensa participación derivó en buscar una inscripción profesional en acuerdo con el militantismo, remodelando su trayectoria profesional para evitar que entrara en conflicto con su disposición militante.

${ }^{16}$ En el sistema educativo francés, les grandes écoles son instituciones de formación superior a las que se accede tras una selección por concurso.

${ }^{17}$ El análisis de Mathieu (2018) permite visibilizar las particularidades de Lyon, así como la interdependencia que une el centro y sus periferias. Su apuesta por el estudio de historias de vida pretende determinar los modos en que la experiencia en los acontecimientos del 68 pesaron en las trayectorias militantes, profesionales y familiares.

${ }^{18}$ En funcionamiento entre 1960 y 1989, este partido representaba el ala más a la izquierda del socialismo.

${ }^{19}$ Idem. 
De la radicalización política a la defensa de Derechos humanos en París. Dos trayectorias CONeCTAdas De Reconversión militante (Envar El Kadri y François Gèze, I 968 -I983)

\section{Moira Cristiá}

trabajando como docente en el Liceo Francés de Montevideo entre 1965 y 1970, y ya había publicado un libro sobre la guerrilla de Tupamaros en Uruguay (LABROUSSE, 1971) y otro sobre la experiencia chilena de la Unidad Popular (LABROUSSE, 1972). El trabajo conjunto se esforzaba en explicar las características del peronismo en ese contexto y el proceso represivo ya iniciado en ese país. Ilustrando la portada del libro, la apropiación gráfica de una imagen del Rosariazo (1969) acentúa la acción rebelde. La fotografía muestra a un joven lanzando un proyectil a la policía, gesto también resaltado como acto heroico por la iconografía de mayo del 68, por ejemplo, en el afiche del Atelier de BeauxArts "La beauté est dans la rue"20.

Desde fines de 1974, agrupándose en un comité de personas con algún vínculo con Argentina, Gèze denunciaba la represión clandestina en ese país. Ese grupúsculo de militantes formó primero el Comité de Soutien aux Luttes du Peuple Argentin (CSLPA, Comité de Apoyo a las Luchas del Pueblo Argentino), que convergió más tarde con otros actores en lo que sería el Collectif pour le boycott de l'organisation par l'Argentine de la coupe du monde de football (COBA). En la evolución de los propósitos de estas asociaciones se aprecia el cambio de perspectiva: del "apoyo a las luchas del pueblo" al boicot del Mundial de Fútbol, es decir, a la denuncia de la dictadura. Luego del primer llamado público a boicotear este evento en el diario Le Monde en octubre de 1977, el colectivo fue fundado a fines de ese año en repudio no solamente a la campaña de legitimación del régimen militar sino también de la complicidad a la que se accedía Francia participando en dicha competición y, peor aún, vendiendo armas a un gobierno del cual existían pruebas concretas de que violaba derechos humanos ${ }^{21}$.

\footnotetext{
${ }^{20}$ Como fue analizado por Cristiá (2011) la misma fotografía fue reproducida artísticamente en 1972 en una obra mural que enviaron los rosarinos Graciela Carnevale, Lía Maisonnave y Juan Pablo Renzi para una muestra contrainformativa en París.

${ }^{21}$ En octubre de 1978, el COBA anunció que se plegaría a la jornada de los comités de Larzac - movimiento de oposición a la extensión de un campo militar en esa región francesa para lo cual se expropiarían terrenos de campesinos - denunciando la venta de armas del gobierno de Giscard d'Estaing a la dictadura argentina. En ese documento se evoca la acción de militantes antiimperialistas de Le Havre encadenándose para impedir la partida del cargo argentino "Río Colorado". Comunicado interno del COBA, 28 oct. 1978. Archivo F. Gèze, Bibliothèque de Documentation Internationale Contemporaine (BDIC).
} 
De la radicalización política a la defensa de Derechos humanos en París. Dos trayectorias CONeCTAdas De Reconversión militante (Envar El Kadri y François Gèze, I 968 -I983)

\section{Moira Cristiá}

Figura 2: Portada de Argentine, révolution et contre-révolutions

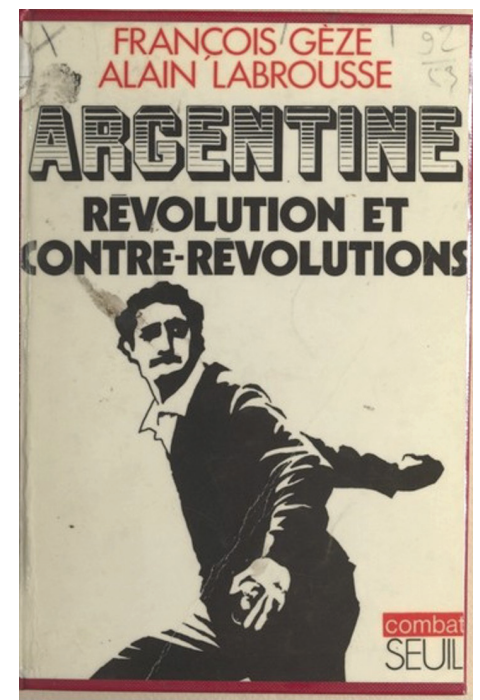

Figura 3: Fotografía publicada en la revista 7 dias, 22 al 28 sep. 1969

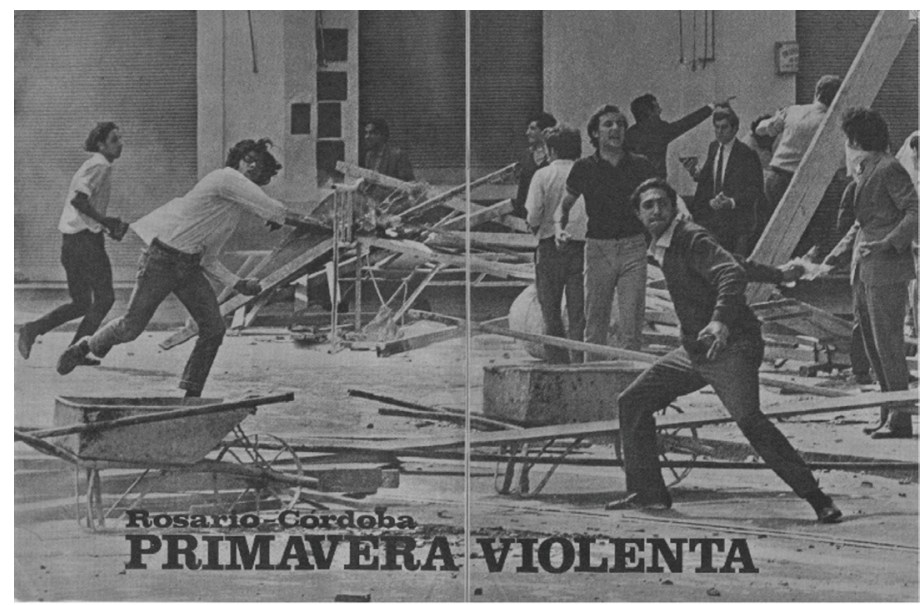

Reanudando el vínculo establecido en Buenos Aires, Gèze invitó a El Kadri y Andreone a las reuniones que se organizaban en el local del Centre d'études et d'initiatives de solidarité internationale (CEDETIM), en los albores de lo que sería el COBA ${ }^{22}$. Inicialmente llamado Centre socialiste de documentation et d'études sur les problèmes du tiers monde, el CEDETIM había sido creado en 1967, en el marco de las luchas de descolonización en Asia y África, ampliando una primera formación fundada dos años antes. Con cierta continuidad con la "cooperación roja" de quienes apoyaron la liberación argelina, el grupo inicial estaba compuesto por militantes combativos (principalmente del PSU) que habían tenido

${ }^{22}$ ENTREVISTA telefónica de la autora a Liliana Andreone, 2 ago. 2016. 
De la radicalización política a la defensa de Derechos humanos en París. Dos trayectorias CONeCTAdas De Reconversión militante (Envar El Kadri y François Gèze, I 968 -I983)

\section{Moira Cristiá}

experiencias profesionales y de cooperación en el Tercer Mundo, lo que les había permitido conocer otras realidades y mirar críticamente el comportamiento francés respecto de esas regiones (ZEROUALI, 2008).

Fue precisamente en ese centro en donde Gèze y Labrousse habían participado de la creación del Comité de Soutien à la lutte révolutionnaire du peuple chilien (Comité de Apoyo a la Lucha Revolucionaria del Pueblo Chileno) durante el verano europeo de 1972, extendiéndose en la creación de comités por toda Francia, y cobrando -después del golpe de estado en Chile- gran incidencia en la denuncia internacional de la dictadura de Pinochet ${ }^{23}$. El local de CEDETIM, en el número 14 de la rue Nanteuil del distrito 15 de París, fue escenario de los primeros debates de acciones de boicot y estrategias a seguir para denunciar la represión en Argentina, donde también circulaban militantes de distintas causas y exiliados de variadas nacionalidades en reuniones de comités de solidaridad que se sucedían en aquella sala.

Como ha sido ampliamente estudiado (BREUIL, 2000; FRANCO, 2008; COMPAGNON, 2008; CONTAMIN; LE NOÉ, 2010), al grupo de militantes que componía el CSLPA se sumaron diversos actores pertenecientes al medio deportivo, conformando el COBA. Esta organización estrechó vínculos con comités de otras latitudes que compartían el mismo propósito ${ }^{24}$, formando un movimiento crítico transnacional con características singulares en cada país (REIN, 2019). Además de la firma de peticiones, solicitadas en diarios, manifestaciones callejeras y difusión de información, el COBA puso en marcha una campaña que incluyó la participación y creatividad de artistas para tener mayor impacto en la opinión pública ${ }^{25}$. Sin embargo, esta voluntad de boicot era también discutida dentro de la comunidad de exiliados argentinos en Francia, muchos de los cuales consideraban que el Mundial podía servir para solicitar concesiones a la dictadura ${ }^{26}$.

Fue durante esta intensa campaña cuando el lenguaje empleado abandonó el tinte revolucionario para centrarse en la defensa de los derechos humanos y en el repudio de la acción represiva de los militares argentinos. Sin embargo, en ese marco también sobrevivieron prácticas ligadas a la acción revolucionaria, como el intento fallido de secuestro del director técnico del equipo francés Michel Hidalgo ${ }^{27}$. Si bien los autores del operativo se presentaron como "trabajadores no pertenecientes a ninguna organización" exigirían, además de la liberación de detenidos, obtener espacio publicitario en los grandes periódicos nacionales e internacionales para explicar la realidad de la represión argentina, la proyección del film

\footnotetext{
${ }^{23}$ ENTREVISTA de Thomas Baumgartner a François Gèze, op. cit.

${ }^{24}$ JANIN, François. La coupe du monde. Le collectif pour le boycottage expose sa tactique. Le Monde, 14 ene. 1978.

${ }^{25}$ GABETTA, Carlos. Entrevista a François Géze. Humor, n. 125, p. 62-64, abr. 1984. Entre ellos se destaca la organización de recitales, campañas gráficas y hasta la elaboración de un disco en repudio al mundial de fútbol.

${ }^{26}$ Idem.

${ }^{27}$ Hidalgo narró en un reportaje televisivo esa tentativa de secuestro: AFFAIRE Hidalgo. TF1 actualités, 23 mayo 1978. INA. Disponible en: https://www.ina.fr/video/CAA7801080201. Acceso en: 14 mayo 2019.
} 
De la radicalización política a la defensa de Derechos humanos en París. Dos trayectorias CONeCTAdas De Reconversión militante (Envar El Kadri y François Gèze, I 968 -I983)

\section{Moira Cristiá}

realizado por el COBA Supporteurs, si vous saviez ("Hinchas, si ustedes supieran") y la participación de personalidades de ese movimiento crítico en los debates televisivos ${ }^{28}$. A pesar de que el proyecto resultó frustrado, los responsables de la acción declararon, en un llamado anónimo, que la finalidad del operativo era "no violenta y humanitaria" y que buscaba "llamar la atención de la hipócrita acción de Francia, que provee material militar a la Argentina"29. Por haber empleado un método violento con esas intenciones - aunque no podemos confirmar su vinculación orgánica con el COBA -, podemos situar el movimiento de boicot al Mundial a mitad de camino de esa conversión militante, a caballo entre "lo viejo y lo nuevo".

\section{Una labor conjunta: la defensa de los derechos humanos}

Fue en el marco de la actividad del COBA que nuestros protagonistas emprendieron el trabajo conjunto en la denuncia de la acción de la dictadura argentina. Tras el Mundial de Fútbol, y a través del abogado y miembro de la Comisión Argentina de Derechos Humanos (CADHU) Eduardo Luis Duhalde ${ }^{30}$, en ese momento exiliado en España, Gèze acordó el envío de dinero del COBA para los familiares de presos políticos en Argentina ${ }^{31}$. Esa organización francesa (que entonces aparece como Collectif de Boycott de la Dictature Argentine) impulsó - entre otras acciones - un cuadernillo de información sobre la venta de armas de Francia. Recordando que ese país era el tercer exportador mundial de armas, el COBA repudiaba su provisión a diferentes dictaduras del Tercer Mundo (Chile, Nicaragua y Sudáfrica) y responsabilizaba al presidente Valérie Giscard d'Estaing ${ }^{32}$.

En ese sentido, por la implicancia y el método, además de la presencia de algunos actores que constituirán luego AIDA (principalmente El Kadri y Andreone), podemos situar la experiencia del COBA como un antecedente de la campańa que llevará adelante aquella asociación por los desaparecidos de Argentina. En AIDA, la colaboración continuó y se amplió a otros grupos, principalmente a $\operatorname{artistas}^{33}$. Si bien esta nueva asociación desplegó una serie de acciones por el país sudamericano desde 1980, un proyecto editorial se logró gracias a esos diálogos entre El Kadri y Gèze. A través de la amistad personal del francés

\footnotetext{
${ }^{28}$ Según se afirma en Le Monde, el diario Le Matin publicó una entrevista bajo identidad reservada: MANIFESTATIONS dans plusieurs villes de province. Le Monde, 26 mayo 1978.

${ }^{29}$ Idem.

${ }^{30}$ Desde los años sesenta, Duhalde (1939/2012) defendió casos de militantes políticos junto a Rodolfo Ortega Peña. En 1974, y siendo diputado nacional, este último fue asesinado por la fuerza parapolicial Triple A.

${ }^{31}$ ROCA, Gustavo [Correspondencia]. Carta enviada desde Madrid como miembro de la CADHU y dirigida a Gèze del COBA. Recibo firmado por Duhalde. 28 nov. 1978. Archivo Gèze, BDIC.

${ }^{32}$ COBA. Dossier noir de vente d'armes françaises à l'Argentine, 1979.

${ }^{33}$ El Estatuto de AIDA refiere a varios artículos de la Declaración Universal de los Derechos Humanos. Fue redactada por el magistrado francés Louis Joinet, quien además de participar de experto independiente de la comisión de trabajo sobre derechos humanos de la ONU en Ginebra, testimoniaría en Buenos Aires en 1985 durante el Juicio a las Juntas.
} 
con el librero y editor François Maspero ${ }^{34}$ - responsable de la publicación de materiales contestarios revolucionarios desde mediados de los cincuenta como Los condenados de la Tierra de Franz Fanon (HAGE, 2010) -, El Kadri presentó una propuesta de libro en abril de 1981. La amistad y confianza entre Maspero y Gèze se plasmaba en que el primero había concedido al segundo la dirección de la colección CEDETIM de su editorial en $1977^{35}$ y, en 1982, le delegaría el mando general de la editorial ${ }^{36}$.

El proyecto de libro fue presentado como la puesta en evidencia del plan sistemático de represión de una cultura popular e intelectual determinada, a la que el régimen juzgaba como peligrosa. El contrato de edición, que establecía un tiraje de 10.000 ejemplares, fue firmado por Envar El Kadri con su apellido materno (Manna) como representante de AIDA ${ }^{37}$. Allí se buscaría exponer, principalmente a través de recortes de prensa argentina representativa de sectores de poder local, evidencias de cómo la cúpula militar censuraba obras, encarcelaba o desaparicía a sus autores. Organizados por área de la vida cultural (televisión, radio, prensa escrita, artes plásticas, cine, música, teatro), los artículos se complementaban con relatos de artistas e intelectuales que ratificaban desde el exilio las consecuencias de la represión en el campo cultural argentino ${ }^{38}$.

Figura 4: Portada del libro publicado por AIDA en 1981

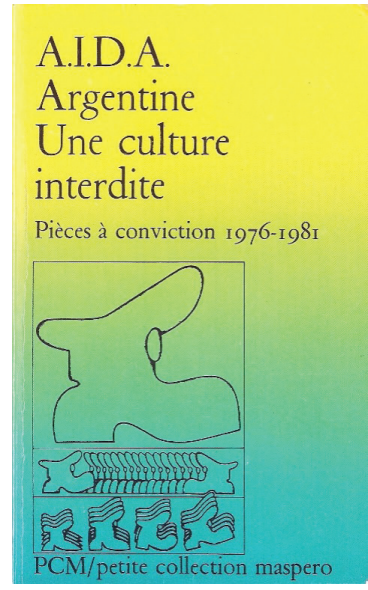

La secuencia de viñetas ilustradas por Héctor Cattolica muestra el avance de tropas constituidas de la fusión de botas y gorros policiales

\footnotetext{
${ }^{34}$ ENTREVISTA telefónica de la autora a Liliana Andreone, 2 ago. 2016.

${ }^{35}$ Según Joseph (2019, p. 186), en esa colección se publicaron, entre 1977 y 1981, seis títulos de clara postura anticolonial: L'impérialisme français y otros cinco dedicados a Brasil, Argelia, Angola, Portugal e Irán respectivamente.

${ }^{36}$ Tras la sesión de la dirección, en 1982, la editorial cambió su nombre por el de Editorial La Découverte.

${ }^{37}$ CONTRATO de edición de Mort à la culture (Argentine, 1976-1980) entre François Maspero y Envar Manna representando AIDA, febrero de 1981. Archivo de AIDA-Francia, La Cartoucherie.

${ }^{38}$ Presentación de proyecto titulado Argentine: mort d'une culture? (Pièces à conviction, 1976-1980), abr. 1981.
} 
De la radicalización política a la defensa de derechos humanos en París. Dos trayectorias CONeCtadas De reconversión militante (Envar El Kadri y François Gèze, I 968 -I983)

\section{Moira Cristiá}

La selección y organización de los materiales fue realizada en la sede del Teatro du Soleil durante los fines de semana mientras El Kadri cumplía la vigilancia nocturna del predio, cuando Andreone y amigos de ambos se sumaban a colaborar ${ }^{39}$. A pesar del contexto general de censura y manipulación de los medios (RISLER, 2018; GAMARNIK, 2012) cuyas direcciones editoriales diluían aquellas noticias entre artículos que normalizaban la situación argentina, justificaban las acciones o directamente legitimaban el régimen - las notas funcionaban como pruebas de la represión cultural en Argentina. Extraídas del marco de un ejemplar de diario, las informaciones aparecían como huellas de un sofisticado sistema represivo de la cultura que iba desde la censura de libros, películas y discos a la desaparición de artistas, pasando por la confección de listas negras y la vigilancia de los programas de estudios, entre otros mecanismos de control.

El protagonismo de François Gèze en el contacto con el editor para posibilitar la publicación, se complementó de su colaboración en algunas traducciones al francés o correcciones de textos, así como de la presentación del libro el día de su lanzamiento en París ${ }^{40}$. Junto a Ariane Mnouchkine, Yves Montand, Claude Lelouch y Julio Cortázar, Gèze presidió el evento que tuvo lugar el 6 de mayo de 1981 en un sindicato de libreros, situado en el Boulevard Saint-Germain ${ }^{41}$. Otras presentaciones del libro en distintas ciudades de Francia (Le Mans, Martigues, Aviñón, Lille, Dijon, Cannes y Lorient) contaron con artistas argentinos como Miguel Ángel Estrella, Mercedes Sosa, Liber Forti, y principalmente del mismo Envar El Kadri, invitado como autor de la iniciativa, pero apareciendo públicamente como "Esteban Caccio" ${ }^{2}$. En el libro, en cambio, su autoría figura bajo el pseudónimo de Juan José Hernández Arregui, protegiendo su verdadera identidad en aquel contexto amenazante y a la vez homenajeando al escritor del peronismo revolucionario fallecido en $1974^{43}$.

\footnotetext{
${ }^{39}$ ENTREVISTA de la autora a Liliana Andreone. Buenos Aires, 5 jun. 2018. En el prefacio de la edición en castellano, sus coordinadores expresan el deseo de "destacar la labor del gestor, compaginador y propulsor de esta denuncia colectiva, ya que, gracias a su paciencia y tenacidad, a la ímproba labor de reunir y clasificar tanto material, ella ha sido posible". Firmado Alberto Adellach, Mariano Aguirre e Ignacio Colombres, Madrid, sep. 1981 (AIDA, 1981b, p. 5).

${ }^{40}$ ENTREVISTA de Laure Adler a François Gèze. Programa radial "Hors Champs", 15 mayo 2014, Radio France Culture. Disponible en: https://www.franceculture.fr/emissions/hors-champs/francois-geze. Acceso en: 14 mayo 2019.

${ }^{41}$ INVITACIÓN de la Editorial Maspero a la presentación del libro en el Cercle de la Librerie, 117 bv. Saint Germain, 75006, 6 mayo 1981. Archivo personal del artista Guillermo Núñez, exiliado en Francia desde 1975. Centro de Documentación del Museo de la Memoria y de los Derechos Humanos, Santiago de Chile. ${ }^{42}$ Así es nombrado en las notas de prensa sobre dichas actividades, cf. AIDA: Argentine, une culture interdite. Le Dauphine Libéré, 1 ago. 1981; L'AIDA en campagne: L'Internationale de la répression passe par Prague... et Buenos-Aires. Ouest-France, 17 jun. 1981; MIGUEL Ángel Estrella à Lille: Argentine, une culture interdite. Nord Eclair, 30 ene. 1982.

${ }^{43}$ En la portada interior del libro aparece indicado "Textos reunidos y presentados por 'Juan José Hernández Arregui' seudónimo adoptado por el autor en homenaje a un gran intelectual peronista, forjador de la consciencia nacional argentina, muerto en Buenos Aires en 1974" (AIDA, 1981).
} 
De la radicalización política a la defensa de Derechos humanos en París. Dos trayectorias CONeCTAdas De Reconversión militante (Envar El Kadri y François Gèze, I 968 -I983)

\section{Moira Cristiá}

Este libro se sumaba a la extensa serie de acciones de AIDA que iban desde actos de repudio durante 1980 (al festival de cine francés en Buenos Aires, a la gira de la Orquesta de París a Argentina, a la visita de José Martínez de Hoz a Francia o a un concierto de Astor Piazzolla en el Teatro de Champs Elysées de París ${ }^{44}$ ) a estructurar una compleja campaña donde la imaginación generara iniciativas revulsivas de índole conceptual y de cuidado estético. En comunicación con el movimiento de derechos humanos argentino, AIDA no sólo se apoyó en los vínculos personales y profesionales de sus miembros, sino que también reforzó su accionar con la contribución de otras asociaciones locales, nacionales o internacionales (CRISTIÁ, 2019).

Figura 5: El Kadri sosteniendo la bandera pintada por el artista mexicano Remigio Valdés de Hoyos para la campaña por cien artistas argentinos desaparecidos de 1981

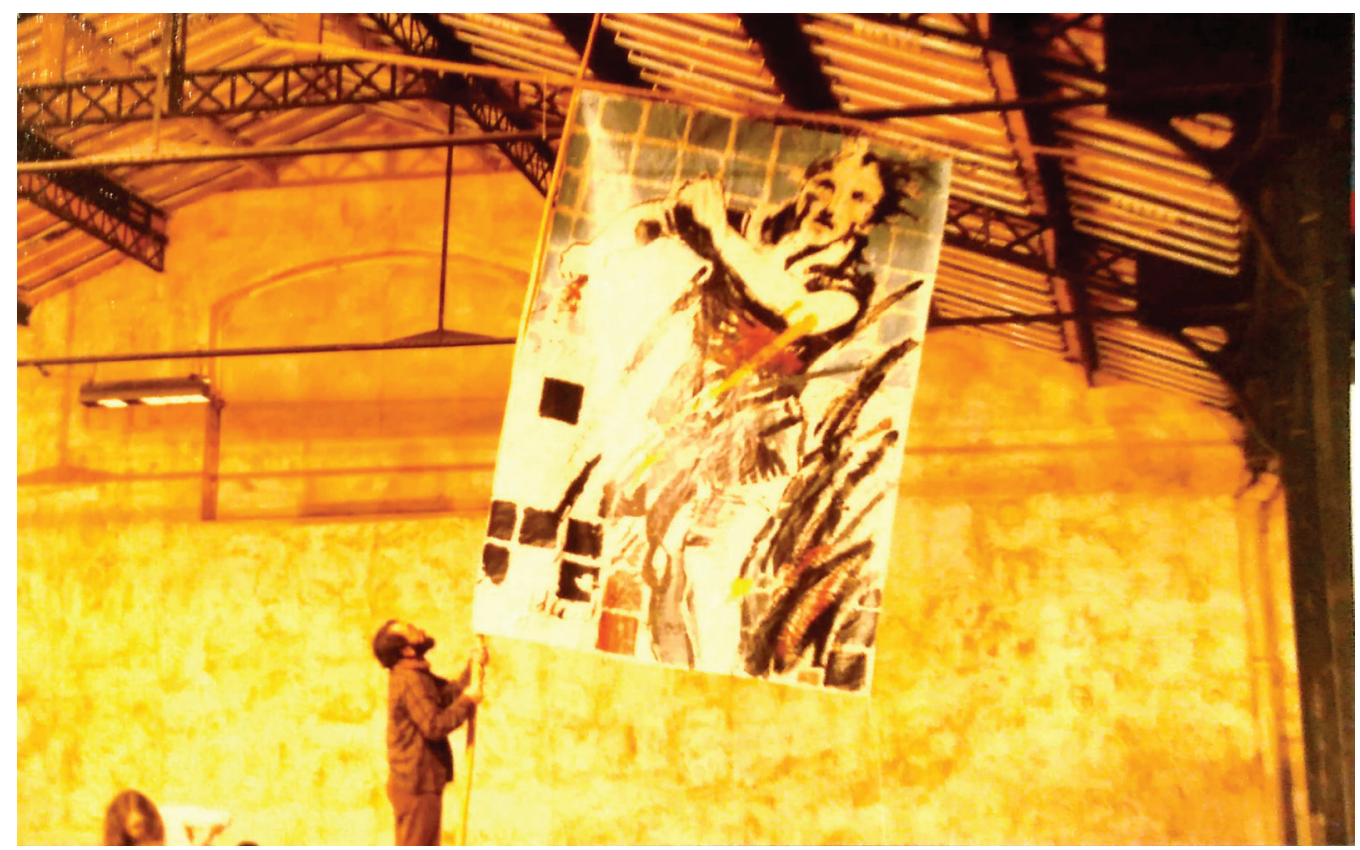

Si bien el joven de la imagen se encuentra en una postura que lo emparenta con la iconografía típica de la revuelta, no se distingue signo de violencia alguno. A diferencia de la resistencia en las barricadas, la protesta de AIDA hacía de las pinturas-banderas sus armas políticas. Fuente: Archivo personal de Liliana Andreone.

Tras la asunción de un gobierno democrático, El Kadri volvió a Argentina, donde continuó involucrado en la producción cultural con una impronta política ${ }^{45}$. Previamente,

\footnotetext{
${ }^{44}$ El boicot al músico argentino respondía a sus declaraciones públicas sobre la dictadura que contribuían a su legitimación. Así lo explican sus detractores en la nota "Adiós Piazzolla", Testimonio Latinoamericano, n. 5, 11 dic. 1980, p. 27.

${ }^{45}$ En particular, en las películas de Fernando Solanas Tangos. El exilio de Gardel (1985), Sur (1988) y El viaje
} 
De la radicalización política a la defensa de Derechos humanos en París. Dos trayectorias CONeCTAdas De Reconversión militante (Envar El Kadri y François Gèze, I 968 -I983)

\section{Moira Cristiá}

junto a Jorge Rulli, publicó una serie de conversaciones en las que, aún desde el destierro en los últimos meses de dictadura, reflexionaban sobre su situación, la evolución de su pensamiento, su lectura del presente y las perspectivas futuras (EL KADRI; RULLI, 1984). Allí se plantearon, como el primer punto a discutir, cuestionarse las razones de haber usado la violencia en algún momento de sus vidas, explicándolo por el "sentimiento exacerbado de justicia, como reacción frente a la injusticia..." (Jorge, p. 14) "nos sentíamos representando una voluntad mayoritaria [el peronismo] a quien se le privaba del gobierno solamente por la fuerza" (Envar, p. 16). En ese mismo libro, El Kadri desarrolla su cambio de postura respecto de los derechos humanos de esta manera:

Siempre creí que el problema de los derechos humanos era algo táctico, que nosotros debíamos emplear para denunciar las injusticias del régimen. Una vez que hiciéramos la Revolución con mayúsculas, se iba a terminar con todas sus explotaciones, empezando por liberar al hombre de la explotación capitalista, dándoles a todos techo, comida, trabajo, educación, sanidad, etc. Miraba con una sonrisa de complacencia a los defensores de los derechos humanos. Pensaba que ellos actuaban así para tranquilizar su conciencia culposa de burgueses [...] una de las cosas que aprendí en el exilio es que la libertad es una e indivisible y que si uno acepta que sea violada en alguna parte del mundo, bajo el pretexto que sea, uno comienza a perder su propia libertad [...] Esta posición es la que me llevó a participar en la fundación de la AIDA o rever las ideas que tenía de asociaciones como Amnistía Internacional o sus similares, que siempre me parecieron buenas para "tranquilizar consciencias" en estos países desarrollados de Europa. [...] Estas asociaciones han nacido en la gran ola de denuncias de los crímenes del nazismo y de los que cometían las potencias colonialistas en los países del Tercer Mundo. Por ejemplo, en Francia, hubo mucha gente que se organizó para protestar por las torturas a las que se sometían a los militantes argentinos. Y eso lo hacían no sólo en nombre del derecho a la autodeterminación del pueblo argentino sino en nombre de los derechos humanos (EL KADRI; RULLI, 1984, p. 97).

El análisis de El Kadri sobre la transformación de su posicionamiento refiere a la perspectiva abierta fuera del país en contacto con la realidad europea, que lo condujo de mirar con cierto desdén el comportamiento político de ciudadanos europeos y organizaciones internacionales de defensa de los derechos humanos, a adherir a esa postura. Asimismo, en una entrevista de 1984 lo explica de manera similar "[en el exilio] Aprendí también a considerar los derechos humanos como los fundamentales de la persona y no como un mero principio táctico que hoy defendemos y mañana aceptariamos violar en nombre de un Partido o de una organización" ${ }^{346}$. A pesar de la tradición de defensa de los derechos humanos existente en Argentina desde

(1992). En 1998, El Kadri falleció en Tilcara mientras acompañaba una gira de Miguel Ángel Estrella.

${ }^{46}$ Reproducido en Cersósimo (2008, p. 61). Copello (2019b) afirma que la CADHU intentaba contribuir con los derechos humanos a los objetivos de la revolución y contrasta su discurso al de la Asamblea Permanente de los Derechos Humanos (APDH) que respondía a tendencias más centristas del paisaje político argentino. 
De la radicalización política a la defensa de derechos humanos en París. Dos trayectorias CONeCtadas De Reconversión militante (Envar El Kadri y François Gèze, I 968 -I983)

\section{Moira Cristiá}

los años treinta, ligada a los sectores liberal-democráticos ${ }^{47}$, en ese contexto manifestó la transformación de su visión de los derechos humanos a partir de conocer otras realidades y experiencias históricas, convicción que se saldó en su participación férrea en AIDA.

En el caso de Gèze, la adaptación de la línea editorial anticolonial de la combativa François Maspero (en donde dirigió la colección CEDETIM), a La Découverte en 1982 coincide con una transformación coyuntural. La asunción del candidato del Partido Socialista François Mitterrand a la presidencia en 1981 se concretó en el marco de una regresión del movimiento masivo en los años setenta de apoyo a esas luchas, lo que Fillieule (2001) denominó la "salida de escena del sujeto revolucionario". En el traspaso de la empresa a Gèze, al elegir un nombre y logo de una colección de la editorial original, el nuevo director situó La Découverte en clara continuidad con Maspero. Sin embargo, su línea editorial - que continuó dirigiendo hasta 2014 - se morigeró: en vez de "libros militantes", desde entonces publicarían "libros de información" bajo "cierta visión del mundo claramente de izquierda"

\section{Conclusión}

La reconstrucción de las trayectorias de El Kadri y Gèze ilustra una trama de experiencias compartidas que evidencian un intercambio de larga data y un trabajo conjunto en acciones de denuncia y proyectos como el libro de AIDA sobre la represión cultural en Argentina. Esta experiencia permite matizar la idea extendida del uso puramente estratégico del lenguaje de los derechos humanos que, sin negar que existió en ciertos momentos y para determinados actores (como lo demuestra el mismo fragmento citado del libro de El Kadri), no puede generalizarse. El cambio de perspectiva del militante argentino estudiado, que incluyó su propio cuestionamiento del uso de la violencia, podría explicar que haya abandonado la publicación de aquel libro sobre Palestina escrito en 1975, movilizado por la urgencia y la prioridad de la defensa de los derechos humanos en el marco de la represión dictatorial. Por su parte, tras su politización durante la efervescencia del 68 y atraído por el clima revolucionario latinoamericano, Gèze viajó a la región en los primeros años setenta y luego creó el "Comité de Apoyo a la Lucha Revolucionaria del Pueblo Chileno". Asimismo, fue por ese motivo que vivió temporalmente en la región, donde entrevistó a El Kadri para el libro que publicó con Labrousse sobre la situación

\footnotetext{
${ }^{47}$ La Liga Argentina de Derechos del Hombre, fundada en 1937 como un espacio de confluencia de distintas tendencias políticas progresistas, velaba por la integridad de los presos políticos. Según Vecchioli (2008), aunque existió una circulación de abogados que se movilizaron por los derechos humanos desde los treinta, su incorporación al espacio transnacional desde los años sesenta permitió su especialización y una consecuente reconfiguración del espacio jurídico y estatal.

${ }^{48}$ ENTREVISTA a François Gèze. Realizado por la Librairie Mollat, 6 ago. 2013. Disponible en: https:// www.youtube.com/watch?v=eeiyupNgNas. Acceso en: 12 abril 2019.
} 
De la radicalización política a la defensa de derechos humanos en París. Dos trayectorias CONeCtadas De Reconversión militante (Envar El Kadri y François Gèze, I 968 -I983)

\section{Moira Cristiá}

argentina en 1975. El ingeniero francés, también experimentó un claro realineamiento del apoyo de procesos revolucionarios y anticoloniales a la doctrina de la defensa de los derechos humanos, lo cual se cristalizó en las múltiples acciones de las agrupaciones a las que perteneció (CSLPA y COBA) y finalmente en la colaboración con su par argentino en el libro de AIDA Argentine: une culture interdite.

Sin considerar estos casos excepcionales ni ampliamente generalizables, en este trabajo fueron estudiados en profundidad como casos testigo que nos permiten comprender más complejamente una serie de experiencias colectivas a partir de una perspectiva conectada. Centrado en ellos - personalidades con cierto reconocimiento y visibilidad -, el estudio recogió coincidencias con otros actores y grupos que formaron una trama de militancias. En ambos casos notamos que sus intereses políticos excedían lo nacional, presentando una sensibilidad internacionalista y una postura tercermundista (que se expresa en el compromiso de Gèze con América Latina y el interés de El Kadri por Palestina). Ambas trayectorias vitales atravesaron fronteras, recorriendo por un tiempo considerable destinos (como Buenos AiresBeirut-Madrid-París (El Kadri), y Toulouse-París-Buenos Aires-París (Gèze), en distintos momentos de sus vidas y coyunturas diversas. Además de considerar este cambio contextual y de la impronta de determinados acontecimientos en la percepción política de los actores, queda además el interrogante del efecto que habrían tenido también las etapas subjetivas en dichas reconversiones militantes, si consideramos la tendencia a una mayor radicalidad en la primera juventud a una moderación de la postura de la edad adulta.

En suma, reconstruir los vínculos de los actores seleccionados resultó fructífero para pensar las maneras en la que la historia de la militancia revolucionaria argentina y la de la "extrema izquierda" francesa confluyeron, e identificar allí conexiones de mutua influencia en las que se "traducen" e interpretan políticamente experiencias contemporáneas. Asimismo, el recorrido demostró que la evolución de la narrativa revolucionaria a la humanitaria no fue exclusiva de los militantes latinoamericanos, sino que se nutrió de un proceso de transformación del clima político global y se manifestó, con sus propias especificidades, en distintas latitudes. En su análisis nos detuvimos en la articulación de los actores, iluminando los modos de experimentar y aprehender la historia nacional en relación a la de aquel otro país de adopción temporaria y los "contagios" e involucramientos habilitados. Podemos suponer que mientras Gèze pensaba y escribía en francés sobre las “contrarrevoluciones” en Argentina, cuestionaba y se posicionaba contra el colonialismo francés y el imperialismo norteamericano, de manera similar a la que El Kadri asumía al reflexionar en español sobre la situación palestina desde El Líbano. En ambos casos, el idioma utilizado refería a un lector potencial al que su libro buscaba interpelar, sugiriendo que se dirigían a sus connacionales. Más tarde, al participar del COBA, Gèze batallaba contra la política del gobierno de Girard d'Estaing, denunciando la provisión irresponsable de armas a dictaduras. Simultáneamente, El Kadri repensó su historia personal en ese nuevo contexto francés, desarmando su prejuicio 
De la radicalización política a la defensa de derechos humanos en París. Dos trayectorias CONeCtadas De Reconversión militante (Envar El Kadri y François Gèze, I 968 -I983)

\section{Moira Cristiá}

respecto de la militancia local y la defensa de los derechos humanos, e incorporándose a una agrupación mayoritariamente europea como AIDA, que se estructuraba bajo esos valores. La escala asumida en este artículo, centrada en dos actores puntuales, permitió analizar el intercambio y la porosidad que estas circulaciones internacionales facultaron, permeando la política de los países involucrados y complejizando la mirada de los partícipes respecto al mundo y la política contemporánea.

\section{Fuentes orales y documentales}

Adiós Piazzolla, Testimonio Latinoamericano, n. 5, p. 27, 11 dic. 1980.

Affaire Hidalgo, TF1 actualités, 23 mayo 1978. INA. Disponible en: https://www.ina.fr/ video/CAA7801080201. Acceso en: 14 mayo 2019.

AIDA: Argentine, une culture interdite, Le Dauphine libéré, 1 ago. 1981

AZNARES, Carlos. Reportaje a El Kadri. Caras y Caretas, n. 2.209, abr. 1984, republicada en Cersósimo (2008).

Comunicado interno del COBA, 28 oct. 1978. Archivo F. Gèze, Bibliothèque de Documentation Internationale Contemporaine (BDIC).

Contrato de edición de Mort à la culture (Argentine, 1976-1980) entre François Maspero y Envar Manna representando AIDA, febr. 1981. Archivo de AIDA-Francia, La Cartoucherie. Entrevista a François Gèze. Realizada por la Librairie Mollat, 6 ago. 2013. Disponible en: https://www.youtube.com/watch?v=eeiyupNgNas, Acceso 12 abr. 2019.

Entrevista de la autora a Fernando Solanas, Olivos, 29 abr. 2017.

Entrevista de la autora a Liliana Andreone, Buenos Aires, 5 jun. 2018.

Entrevista de la autora a Liliana Andreone, París, 28 abr. 2016.

Entrevista de la autora a Marie-Pascale Chevance Bertin, París, 5 mayo 2016.

Entrevista de Laure Adler a François Gèze. Programa radial "Hors Champs", 15 mayo 2014, Radio France Culture. Disponible en: https://www.franceculture.fr/emissions/hors-champs/ francois-geze. Acceso en: 14 mayo 2019.

Entrevista de Thomas Baumgartner a François Gèze. Programa radial "À voix nue", Radio France Culture, 21 oct. 2013. Disponible en: https://www.franceculture.fr/emissions/voixnue/francois-geze-15. Acceso en: 14 mayo 2019.

Entrevista telefónica de la autora a Liliana Andreone, 2 ago. 2016.

GABETTA, Carlos. Entrevista a François Géze. Humor, n. 125, p. 62-64, abr. 1984.

Invitación de la Editorial Maspero a la presentación del libro en el Cercle de la Librerie, 117 bv. Saint Germain, 75006, 6 mayo 1981. Archivo personal del artista Guillermo Núnez. 
De la radicalización política a la defensa de derechos humanos en París. Dos trayectorias CONeCtadas De reconversión militante (Envar El Kadri y François Gèze, I 968 -I983)

\section{Moira Cristiá}

Centro de Documentación del Museo de la Memoria y de los Derechos Humanos, Santiago de Chile.

JANIN, François. La coupe du monde. Le collectif pour le boycottage expose sa tactique. Le Monde, 14 ene. 1978.

L'aida en campagne: L'Internationale de la répression passe par Prague... et Buenos-Aires, Ouest-France, 17 jun. 1981.

Manifestations dans plusieurs villes de province, Le Monde, 26 mayo 1978.

Miguel Ángel Estrella à Lille: Argentine, une culture interdite, Nord Eclair, 30 ene. 1982.

MONCALVILlO, Mona. Entrevista a Envar El Kadri. Humor, n. 126, p. 55, abr. 1984, republicada en Cersósimo (2008).

PENAA, Fernando Martín; PONCE, Alberto. Cómo se hizo "El exilio de Gardel". 85 min., Argentina, 2010.

Proyecto titulado Argentine: mort d'une culture? (Pièces à conviction, 1976-1980), abr. 1981. REVUELTA, Manuel. Las 'campañas orquestadas', denunciadas por el gobierno argentino. El Pais, 26 ago. 1976.

REVUELTA, Manuel. Muerte del poeta Francisco Urondo. El Pais, 3 jul. 1976.

ROCA, Gustavo [Correspondencia]. Carta enviada desde Madrid como miembro de la CADHU y dirigida a Gèze del COBA. Recibo firmado por Duhalde. 28 nov. 1978. Archivo Gèze, BDIC.

COBA. Dossier noir de vente d'armes françaises à l'Argentine, 1979.

\section{Referencias}

AIDA. Argentine: une culture interdite (Pièces à conviction 1976-1980). Paris: Maspero, 1981.

AIDA. Argentina: cómo matar la cultura. Madrid: Revolución, 1981.

ANGUITA, Eduardo; CAPARRÓS, Martín. La voluntad. Una historia de la militancia revolucionaria en la Argentina. Tomo 1 (1966-1973). Buenos Aires: Planeta/Booket, 2006. BERNARD, Carmen. El reto de las historias conectadas. Historia Crítica, dossier “Circulaciones y trayectorias, siglos XVI-XIX”, n. 70, p. 3-22, oct./dic. 2018.

BOIMVASER, Jorge. Los sospechosos de siempre. Historia del espionaje en Argentina. Buenos Aires: Editorial Planeta, 2000.

BREUIL, Xavier. Enjeux politiques de la coupe du monde de football 1978 en Argentine. Études des mouvements de boycott en France et en Europe. Mémoire de maîtrise d'Histoire: Université 
De la radicalización política a la defensa de derechos humanos en París. Dos trayectorias CONeCtadas De Reconversión militante (Envar El Kadri y François Gèze, I 968 -I983)

Moira Cristiá

de Metz, 2000.

CERSOSIMO, Facundo. Envar El Kadri. Historias del peronismo revolucionario. Buenos Aires: Colihue, 2008.

COMPAGNON, Olivier. Un boycott avorté: le Mundial argentin de 1978. In: ARTIÈRES, Philippe; ZANCARINI-FOURNEL, Michelle (dir.). 68. Une histoire collective (19621981). París: La Découverte, 2008. p. 697-701.

CONFINO, Hernán, Exilio, debate y ruptura. Los balances de la Contraofensiva montonera de 1979 y la constitución de 'Montoneros 17 de octubre'. Anuario, n. 31, 2019. Disponible en: https://doi.org/10.35305/aeh.v0i31.273. Acceso en: 14 mayo 2019.

CONTAMIN, Jean-Gabriel; LE NOÉ, Olivier. La coupe est pleine Videla! Le Mundial 1978 entre politisation et dépolitisation. Le Mouvement Social, v. 1, n. 230, p. 27-46, 2010.

COPELLO, David. Jacques Vergès, Rupture Strategy and the Argentinean New Left: Circulations and Adaptations of a Judiciary Theory. Global Society, v. 33, n. 3, p. 348-364, 2019a.

COPELLO, David. Faire la révolution par les droits de l'homme: un phénomène d'imbrication militante dans l'Argentine des années 1970 et 1980. Revue Française de Science Politique, Fondation Nationale des Sciences Politiques, v. 69, n. 4, p. 577-600, 2019 b.

CORTINA, Eudald. Internacionalismo y Revolución Sandinista: proyecciones militantes y reformulaciones orgánicas en la izquierda revolucionaria argentina. E.I.A.L., v. 28, n. 2, 2017.

CRENZEL, Emilio. Los derechos humanos, una verdad evidente de la democracia en la Argentina. Estudios Digital, n. 29, p. 73-91, sept. 2013. Disponible en: https://doi. org/10.31050/re.v0i29.5340. Acceso en: 14 mayo 2019.

CRISTIÁ, Moira. Reflejos imaginarios entre Francia y Argentina. Circulación de personas, ideas e imágenes alrededor de mayo del 68. Revista Afuera. Estudios de crítica cultural, n. 10, mayo 2011.

CRISTIÁ, Moira. El drama argentino en una capital de los derechos humanos. Articulaciones de asociaciones, repudio y acciones de denuncia en escenarios parisinos (1977-1983). Revista de la Red Intercátedras de Historia de América Latina Contemporánea, v. 6, n. 10, jun. 2019. Disponible en: https://revistas.unc.edu.ar/index.php/RIHALC/article/view/24494. Acceso en: 14 mayo 2019.

CUCHETTI, Humberto. Régis Debray, intellectuel engagé. De révolutionnaire professionnel à conseiller d'État. Canadian Journal of Latin American and Caribbean Studies / Revue canadienne des études latino-américaines et caraïbes, v. 44, p. 83-104, 2018.

DOUKI, Caroline; MINARD, Philippe. Histoire globale, histoires connectées: un changement d'échelle historiographique?. Revue d'histoire moderne et contemporaine, v. 54, 
De la radicalización política a la defensa de derechos humanos en París. Dos trayectorias CONeCtadas De Reconversión militante (Envar El Kadri y François Gèze, I 968 -I983)

Moira Cristiá

n. 4 bis, p. 7-21, 2007.

EL KADRI, Envar; RULLI, Jorge. Diálogos en el exilio. Buenos Aires: Foro Sur, 1984.

EL KADRI, Envar. Palestina, una lucha del tercer mundo, (mimeo), 1975.

FILLIEULE, Olivier. Propositions pour une analyse processuelle de l'engagement individuel. Post scriptum. Revue française de science politique, n. 51, 1-2, p. 199-215, 2001.

FRANCO, Marina. Solidaridad internacional, exilio y dictadura en torno al Mundial de 1978. In: YANKELEVICH, Pablo; JENSEN, Silvina (comps.). Exilios. Destinos y experiencias bajo la dictadura militar. Buenos Aires: Libros del Zorzal, 2007.

FRANCO, Marina. El exilio. Argentinos en Francia durante la última dictadura. Buenos Aires: Siglo XXI, 2008.

FERNÁNDEZ BARRIO, Facundo; GONZÁLEZ TIZÓN, Rodrigo. De la ESMA a Francia: hacia una reconstrucción histórica del Centro Piloto de París. Folia Histórica del Nordeste, n. 38, p. 99-134, mayo/ago. 2020.

GAMARNIK, Cora. Fotografía y dictaduras: estrategias comparadas entre Chile, Uruguay y Argentina. Nuevo Mundo Mundos Nuevos, n. 12, jun. 2012. Disponible en: http://journals. openedition.org/nuevomundo/63127. Acceso en: 14 mayo 2019.

GÈZE, François; LABROUSSE, Alain. Argentine, révolution et contre-révolutions. Paris: Seuil, 1975.

GREDA PORTERO, José Manuel; HELM, Christian. Solidaridad con la revolución sandinista. Comparativa de redes transnacionales: los casos de la república federal de Alemania y España. Naveg@merica. Revista electrónica editada por la Asociación Española de Americanistas, n. 17, 2016. Disponible en: http://revistas.um.es/navegamerica/article/ view/271921. Acceso en: 13 mayo 2019.

GRUZINSKI, Serge. Les mondes mêlés de la Monarchie catholique et autres 'connected histories'. Annales. Histoire, Sciences Sociales, v. 56, n. 1, p. 85-117, 2001.

HAGE, Julien. Feltrinelli, Maspero, Wagenbach: une nouvelle génération d'éditeurs politiques d'extrême gauche en Europe occidentale, 1955-1982. Histoire comparée, histoire croisée. Tesis de Doctorado dirigida por M. Jean-Yves Mollier, Université de Versailles, Saint-Quentinen-Yvelines, 2010.

JENSEN, Silvina. Los exiliados argentinos y los sentidos del Núremberg: de recurso pedagógico a estrategia de persecución penal de los crímenes de la última dictadura militar (1976-1983). Folia Histórica del Nordeste, n. 34, p. 129-147, ene./abr. 2019.

LABROUSSE, Alain. L'Expérience chilienne: réformisme ou révolution?. Paris: Éditions du Seuil, 1972.

LABROUSSE, Alain. Tupamaros: Guérrilla urbaine en Uruguay. Paris: Éditions du Seuil, 1971. 
De la radicalización política a la defensa de derechos humanos en París. Dos trayectorias CONeCtadas De Reconversión militante (Envar El Kadri y François Gèze, I 968 -I983)

\section{Moira Cristiá}

LEVITT, Peggy; KHAGRAM, Sanjeev (ed.). The Transnational Studies Reader: intersections and innovations. New York: Routledge, 2008.

MARCHESI, Aldo. Hacer la revolución. Guerrillas latinoamericanas de los 60 a la caída del muro. Buenos Aires: Siglo XXI, 2019.

MARKARIAN, Vania. Idos y recién llegados: la izquierda uruguaya en el exilio y las redes transnacionales de derechos humanos, 1967-1984. México: Ediciones La Vasija/Correo del Maestro y CEIU, 2006.

MATHIEU, Lilian (dir.). Lyon en luttes dans les années 68. Lieux et trajectoires de la contestation. Lyon: Presses Universitaires de Lyon, 2018.

MOINE, Caroline. 'Votre combat est le nôtre'. Les mouvements de solidarité internationale avec le Chili dans l'Europe de la Guerre froide. Monde(s), v. 2, n. 8, p. 83-104, 2015.

PAGIS, Julie. Incidences biographiques du militantisme en mai 68. Sociétés contemporaines, v. 4, n. 84, p. 25-51, 2011.

REIN, Raanan. Solidaridad internacional y protestas transnacionales contra la Copa Mundial de Fútbol 1978. Cuadernos de Aletheia, n. 3, p. 29-72, 2019.

RISLER, Julia. La acción psicológica. Dictadura, inteligencia y gobierno de las emociones 19581981. Buenos Aires: Tinta Limón, 2018.

ROBLEDO, Pablo. Montoneros y Palestina. De la revolución a la dictadura. Planeta: Buenos Aires, 2018.

JOSEPH, Camille. Las editoriales Maspero y la Découverte frente a lo 'extranjero'. In: SAPIRO, Gisèle (comp.) Las contradicciones de la globalización editorial. Bogotá: Uniandes, 2019. p. 177-196.

SLATMAN, Melisa. Actividades extraterritoriales represivas de la Armada Argentina durante la última dictadura civil-militar de Seguridad Nacional (1976-1983). Aletheia, v. 3, n. 5, 2012.

VECCHIOLI, Virginia. Redes transnacionales y profesionalización de los abogados de derechos humanos en la Argentina. In: SANTAMARÍA, Ángela; VECCHIOLI, Virginia (eds.). Derechos humanos en América Latina. Mundialización y circulación internacional del conocimiento experto jurídico. Bogotá: CEPI-Universidad del Rosario, 2008. p. 31-62.

ZEROUALI, Abderrahim. Le CEDETIM, de la 'coopération rouge' à l'altermondialisme. In: ARTIÈRES, Philippe; ZANCARINI-FOURNEL, Michelle (dir.). 68. Une histoire collective (1962-1981). París: La Découverte, 2008. p. 559-565. 